\title{
Chronic chest pain and paresthesia after video-assisted thoracoscopy for primary pneumothorax
}

\author{
Maria Cattoni ${ }^{1}$, Nicola Rotolo ${ }^{1}$, Maria Giovanna Mastromarino ${ }^{2}$, Giuseppe Cardillo ${ }^{2}$, Mario Nosotti ${ }^{3}$, \\ Paolo Mendogni ${ }^{3}$, Alessandro Rizzi ${ }^{4}$, Federico Raveglia ${ }^{4}$, Alessandra Siciliani ${ }^{5}$, Erino Angelo Rendina ${ }^{5}$, \\ Lucio Cagini $^{6}$, Alberto Matricardi ${ }^{6}$, Pier Luigi Filosso ${ }^{7}$, Erika Passone ${ }^{7}$, Stefano Margaritora ${ }^{8}$, \\ Maria Letizia Vita ${ }^{8}$, Pietro Bertoglio ${ }^{9}$, Andrea Viti ${ }^{9}$, Lorenzo Dominioni ${ }^{1}$, Andrea Imperatori ${ }^{1}$
}

${ }^{1}$ Center for Thoracic Surgery and Center for Minimally Invasive Surgery, Department of Medicine and Surgery, University of Insubria, Varese, Italy; ${ }^{2}$ Unit of Thoracic Surgery, Regional Hospital San Camillo-Forlanini, Rome, Italy; ${ }^{3}$ Thoracic Surgery and Lung Transplantation Unit, Fondazione IRCCS Ca' Granda Ospedale Maggiore Policlinico, Milan, Italy; ${ }^{4}$ Thoracic Surgery, ASST Santi Paolo e Carlo, Ospedale San Paolo, Milan, Italy; ${ }^{5}$ Department of Thoracic Surgery, Sapienza University of Rome, Rome, Italy; ${ }^{6}$ Department of Thoracic Surgery, University of Perugia Medical School, Perugia, Italy; ${ }^{7}$ Department of Thoracic Surgery, Azienda Ospedaliera Universitaria Città della Salute e della Scienza di Torino, Turin, Italy; ${ }^{8}$ Department of General Thoracic Surgery, Fondazione Policlinico Universitario “A. Gemelli”, IRCCS, Università Cattolica del Sacro Cuore, Rome, Italy; ${ }^{9}$ Division of Thoracic Surgery, IRCCS, Sacro Cuore-Don Calabria Hospital, Negrar di Valpolicella,Verona, Italy

Contributions: (I) Conception and design: A Imperatori, N Rotolo, M Cattoni; (II) Administrative support: L Cagini, C Cardillo, PL Filosso, A Imperatori, S Margaritora, M Nosotti, F Raveglia, EA Rendina, N Rotolo, A Viti; (III) Provision of study materials or patients: All authors. (IV) Collection and assembly of data: P Bertoglio, M Cattoni, MG Mastromarino, A Matricardi, P Mendogni, E Passone, A Rizzi, A Siciliani, ML Vita; (V) Data analysis and interpretation: L Cagini, C Cardillo, M Cattoni, L Dominioni, PL Filosso, A Imperatori, S Margaritora, M Nosotti, F Raveglia, EA Rendina, N Rotolo, A Viti; (VI) Manuscript writing: All authors; (VII) Final approval of manuscript: All authors.

Correspondence to: Nicola Rotolo, MD. Center for Thoracic Surgery, Department of Medicine and Surgery, University of Insubria, Via Guicciardini 9 , 21100 Varese, Italy. Email: nicola.rotolo@uninsubria.it.

Background: This study aims to identify clinical and surgical risk factors for chronic chest pain and paresthesia after video thoracoscopic surgery for primary spontaneous pneumothorax.

Methods: We retrospectively collected the data of 1,178 consecutive patients $<40$-years-old undergoing video thoracoscopic surgery for primary spontaneous pneumothorax in 9 Italian centers in 2007-2017. Cases with <2-month follow-up were excluded, leaving 920 patients [80\% male; median age: 21 (IQR, 18-27) years] for statistical analysis. The following risk factors for chronic chest pain and chronic paresthesia were assessed by univariable and multivariable Cox regression model: age, gender, cannabis smoking, video thoracoscopy ports number, pleurodesis technique (partial pleurectomy/pleural electrocauterization/pleural abrasion/talc poudrage), chest tube size (24/28 F), postoperative chest tube stay.

Results: Blebs/bullae resection with pleurodesis was performed in 732 (80\%) cases; pleurodesis alone in 188 (20\%). During a median follow-up of 68 (IQR: 42-95) months, chronic chest pain developed in $8 \%$ of patients, chronic chest paresthesia in $22 \%$; $0.5 \%$ of patients regularly assumed painkillers. Chronic chest pain was independently associated with partial pleurectomy/pleura abrasion $(\mathrm{P}<0.001)$ and postoperative chest tube stay $(\mathrm{P}=0.019)$. Chronic chest paresthesia was independently associated with pleurodesis by partial pleurectomy $(\mathrm{P}<0.001)$, chest tube stay $(\mathrm{P}=0.035)$ and $28 \mathrm{~F}$ chest tube $(\mathrm{P}<0.001)$.

Conclusions: After video thoracoscopic surgery for primary spontaneous pneumothorax, the incidence of chronic chest pain and paresthesia was significantly lower when pleurodesis was performed by pleural electrocauterization or talc poudrage, and chest tube was removed early. A $24 \mathrm{~F}$ chest tube was associated with lower risk of chronic chest paresthesia.

Keywords: Chronic chest pain; chronic chest paresthesia; video-assisted thoracoscopic surgery; primary spontaneous pneumothorax

(c) Journal of Thoracic Disease. All rights reserved. 
Submitted Sep 10, 2020. Accepted for publication Nov 27, 2020.

doi: $10.21037 /$ jtd-20-2860

View this article at: http://dx.doi.org/10.21037/jtd-20-2860

\section{Introduction}

After video-assisted thoracic surgery (VATS) for treatment of primary spontaneous pneumothorax, 3-63\% of patients complain about persistence of ipsilateral chest pain and/ or paresthesia, even several years after surgery (1-5). Identification and avoidance of risk factors associated with these complications may improve the quality of life after surgery for spontaneous pneumothorax, a disease mainly occurring in young subjects.

In the literature, only few studies investigated chronic pain and paresthesia as long-term outcomes of VATS for primary spontaneous pneumothorax and little information exists about risk factors for chronic pain and paresthesia that occur after this surgical procedure.

This multicentric study aims to identify clinical and surgical variables associated with chronic chest pain and chronic paresthesia after VATS for primary spontaneous pneumothorax in young patients. We present the following article in accordance with the STROBE reporting checklist (6) (available at http://dx.doi.org/10.21037/jtd20-2860).

\section{Methods}

We retrospectively collected the relevant clinical and surgical data of all patients $\leq 40$-year-old who underwent VATS for primary spontaneous pneumothorax in 9 Italian thoracic surgery centers in the period 2007-2017. All records reviewed were defined a priori and de-identified data were transmitted from the centers to the data analysis unit. The study was conducted in accordance with the Declaration of Helsinki (as revised in 2013). The study was approved by the institutional ethics committee (n: 64/2018). Individual patient consent was waived due to the retrospective nature of the study.

For each case we collected the following records: age, gender, smoking habit (tobacco, cannabis), type of surgical indication, VATS side and ports number, lung resection, pleurodesis technique, surgery duration, chest tube size measured in French catheter scale (F), postoperative chest tube stay, 30-day postoperative complications. All records refer to the period in which patients underwent VATS for pneumothorax.

Regarding pleurodesis technique, we defined partial pleurectomy as partial removal of parietal pleura from II to VI/VII intercostal space; pleural electrocauterization as performing horizontal and vertical electrocautery incisions of parietal pleura surface from II to VI/VII intercostal space; pleural abrasion as scrapping parietal pleura surface from II to VI/VII intercostal space; talc poudrage as 2$10 \mathrm{gr}$ sterile talc insufflation through VATS ports.

During postoperative course the chest tube was managed according to each center protocol; notably, three centers, totaling 203 patients, in the initial years of the study period routinely kept chest tube in place for at least 5 days after surgery, despite the absence of postoperative complications.

All patients were followed-up by telephone interview in order to assess the presence and intensity of ipsilateral chest pain and paresthesia and to verify the need and frequency of pain medications. A-priori decided, closedended and rating questions were asked to investigate these possible complications (see Supplementary material for the questionnaire used). The telephone interviews were conducted by a clinician from each center. Patients with follow-up $<2$ months or incomplete data about chest pain and paresthesia at follow-up were excluded from the study.

We defined chronic chest pain as any ipsilateral thoracic pain $\geq 3$ on Numerical Rating Scale (NRS), persisting at least 2 months after surgery and not related to thoracic trauma or chronic infection or other disease/event $(7,8)$. Chronic chest paresthesia was defined as ipsilateral thoracic numbness or disordered sensation distinguishable from wound pain and persisting at least 2 months after surgery $(2,7,8)$. Univariable and multivariable analyses were performed to identify risk factors associated with chronic chest pain and chest paresthesia. Variables included in the analysis were: age, gender, cannabis smoking, VATS ports number, pleurodesis technique, chest tube size and postoperative chest tube stay.

\section{Statistical analysis}

Continuous data were reported as median and interquartile range (IQR). Categorical and count data were presented as frequencies and percentages and compared using Chi- 
Table 1 Demographic and clinical characteristics of 920 patients $\leq 40$-year-old undergoing VATS for primary spontaneous pneumothorax

\begin{tabular}{lc}
\hline Patients' characteristics & Value \\
\hline Age, median [IQR] [years] & $21[18-27]$ \\
Male, $\mathrm{n}[\%]$ & $738[80]$ \\
Current/former tobacco smoker, $\mathrm{n}[\%]$ & $340[38]^{\dagger}$ \\
Active cannabis smoking, n [\%] & $59[7]^{\ddagger}$ \\
Surgical indication, $\mathrm{n}[\%]^{\S}$ & \\
Second ipsilateral pneumothorax & $595[65]$ \\
Persistent air-leaks [>5 days] & $166[18]$ \\
First contralateral pneumothorax & $113[12]$ \\
Synchronous bilateral pneumothorax & $25[3]$ \\
Spontaneous hemo-pneumothorax & $7[1]$ \\
High-risk occupation & $5[<1]$ \\
Radiologically demonstrated large bullae & $1[<1]$ \\
\hline
\end{tabular}

${ }^{\dagger}$, data not available in 31 patients; ${ }^{\ddagger}$, data not available in 81 patients; ${ }^{\S}$, data not available in 8 patients. VATS, video-assisted thoracoscopic surgery; IQR, interquartile range.

square test or Fisher's exact test if any expected frequency was less than 5. Univariable and multivariable analyses were performed by Cox regression model, excluding 38 patients who underwent redo surgery for postoperative complications (hemothorax/persistent air-leak) or pneumothorax recurrence and 26 with these data not available. Multivariable analysis included variables that were statistically significant in univariable analysis. A P value $<0.05$ was considered statistically significant. Statistical analysis was performed using SPSS 24.0 software (IBM Corp, Armonk, NY, USA).

\section{Results}

Between 2007 and 2017, 1,178 consecutive patients $\leq 40$-year-old underwent VATS for primary spontaneous pneumothorax in 9 centers. A total of 258 patients (223 with incomplete data about pain and/or paresthesia at follow-up and 35 with $<2$-month follow-up), were excluded from the study, leaving 920 cases for statistical analysis.

Patients' demographic and clinical characteristics are shown in Table 1.

All surgical procedures were performed by VATS, under general anesthesia. The VATS approach was triportal in
556 cases (61\%), biportal in $325(35 \%)$ and uniportal in 37 (4\%) and in 2 cases this data was not specified. The vast majority of patients $(732,80 \%)$ underwent both blebs/ bullae resection and pleurodesis; pleurodesis alone was performed in 188 patients. Pleurodesis was achieved by talc poudrage in 313 patients (34\%), partial pleurectomy in $196(21 \%)$, pleural electrocauterization in $152(17 \%)$, pleural abrasion in 111 (12\%). In 148 cases (16\%) more than one pleurodesis method was performed during the same operation. Median surgery duration was 60 (IQR: 26-85) minutes. After surgery, in all cases a chest tube was left in place: $24 \mathrm{~F}$ in $379 / 850$ (46\%) cases, $28 \mathrm{~F}$ in $471 / 850$ (55\%); in 70 cases the tube size data was missing. Chest tube, managed accordingly to each center protocol, was removed after a median of 5 (IQR: 4-6) days.

Postoperative mortality was nil. Early postoperative morbidity was $9.3 \%$ (84/903). Persistent air-leak ( $>5$ days) was recorded in 63 patients (7\%) with 4 patients requiring redo VATS. Postoperative ipsilateral hemothorax developed in 9 patients (1\%); this complication required surgery for hemostasis in 6 patients and blood transfusion in 3. As other postoperative complications we recorded: wound infection in $4(0.4 \%)$ cases, arrythmia in $3(0.3 \%)$, contralateral spontaneous pneumothorax in $2(0.2 \%)$, chylothorax in $1(0.1 \%)$, empyema in $1(0.1 \%)$ and pleura effusion in 1 $(0.1 \%)$. Median postoperative length of stay was 6 (IQR: 4-7) days. Pneumothorax recurred ipsilaterally in 73/909 cases (8\%) after a median of 6 (IQR: 1.2-24) months. Of these, 21 patients underwent clinical-radiological monitoring, 15 were treated by chest tube, 9 by chest tube and talc slurry, and 28 by re-operation ( 26 by redo-VATS and 2 by thoracotomy).

During a median follow-up of 68 (IQR: 42-95) months, $75 / 920$ patients (8\%) developed chronic chest pain, with 7\% assuming pain medications in rare occasion (less than once a month) and $0.5 \%$ assuming analgesics at least every week. No patient was under painkillers chronic treatment before surgery. Chronic chest pain rate stratified by pleurodesis technique was $18 \%$ after partial pleurectomy, $18 \%$ after pleural abrasion, $3 \%$ after pleural electrocauterization and $0.3 \%$ after talc poudrage. Among patients with $28 \mathrm{~F}$ chest tube, chronic chest pain occurred in $11 \%$ cases; among those with $24 \mathrm{~F}$ chest drainage in $2 \%$ cases. At univariable analysis, pleurodesis technique, chest tube size and chest tube length of stay were associated with chronic chest pain (Table 2). Pleurodesis technique and chest tube duration were confirmed to be independently associated with chronic chest pain at multivariable analysis (Table 2). 
Table 2 Risk factors for chronic chest pain: univariable and multivariable analyses by binary logistic regression

\begin{tabular}{|c|c|c|c|c|}
\hline Risk factor & \multicolumn{2}{|c|}{ Univariable analysis } & \multicolumn{2}{|c|}{ Multivariable analysis } \\
\hline Age, years $(+1)$ & $1.03(0.99-1.07)$ & 0.10 & - & - \\
\hline Gender (male vs. female) & $1.17(0.66-2.08)$ & 0.59 & - & - \\
\hline Cannabis smoking (no vs. yes) & $1.21(0.52-2.80)$ & 0.66 & - & - \\
\hline \multicolumn{5}{|l|}{ Pleurodesis technique } \\
\hline Partial pleurectomy & Ref. & & Ref. & \\
\hline Pleural electrocauterization & $0.16(0.06-0.42)$ & $<0.001$ & $0.08(0.18-0.32)$ & 0.001 \\
\hline Pleural abrasion & $0.89(0.48-1.62)$ & 0.69 & $0.76(0.36-1.58)$ & 0.47 \\
\hline Postoperative chest tube stay, days $(+1)$ & $1.08(1.04-1.11)$ & $<0.001$ & $1.09(1.01-1.16)$ & 0.019 \\
\hline
\end{tabular}

OR, odds ratio; $\mathrm{Cl}$, confidence interval; VATS, video-assisted thoracoscopic surgery; Ref., reference; F, French.

Chronic chest paresthesia was detected in 201/915 patients (22\%). Chronic chest paresthesia occurred in 56\% of patients after partial pleurectomy, in $27 \%$ after pleural abrasion, in $9 \%$ after pleural electrocauterization and in $6 \%$ after talc poudrage. The occurrence of chronic chest paresthesia was $27 \%$ using $28 \mathrm{~F}$ chest tube and $7 \%$ with the $24 \mathrm{~F}$. At univariable analysis pleurodesis technique, chest tube size and chest tube length of stay were associated with chronic chest paresthesia (Table 3). Pleurodesis technique, chest tube size and chest tube duration were confirmed to be independently associated with chronic chest paresthesia at multivariable analysis (Table 3).

Interestingly, no patients with chronic chest pain and/ or paresthesia reported any limitations in their daily life activities referable to these complications.

VATS ports number was not associated with chronic chest pain nor with chronic chest paresthesia at univariable analysis (Table 2, Table 3). In detail, $8 \%$ patients reported chronic chest pain after bi/triportal VATS, and 3\% after uniportal approach. Chronic chest paresthesia occurred in $22 \%$ of patients after bi/triportal VATS and in $14 \%$ after uniportal.

To analyze the impact of follow-up time on chronic chest pain and paresthesia we divided patients in five groups according to patients' length of follow-up: $>2$ and $\leq 12$ months; $>12$ and $\leq 24$ months; $>24$ and $\leq 36$ months; $>36$ and $\leq 60$ months; $>60$ months. In detail, chronic chest pain rates were $10 \%, 14 \%, 18 \%, 10 \%$ and $5 \%$, respectively. Chronic chest paresthesia rates were 23\%, 40\%, 27\%, $22 \%$ and $19 \%$ respectively. After 90 months of followup, chronic chest and paresthesia rates remained relatively stable ( $7 \%$ and $24 \%$, respectively).

Finally, we observed a significant reduction of chronic chest pain $(\mathrm{P}=0.008)$ and paresthesia $(\mathrm{P}<0.001)$ during the first years of the study period (between 2007-2009 and 2007-2011, respectively). Subsequently, chronic chest pain and paresthesia incidences showed inconstant fluctuations (Figure 1).

\section{Discussion}

Blebs/bullae resection and pleurodesis by VATS is the standard surgical approach for primary spontaneous pneumothorax. Numerous publications focused on longterm outcomes after this procedure, but only few studies evaluated the persistence of ipsilateral chest pain and paresthesia at long-term follow-up and investigated variables possibly related to them. Our study finds that chronic chest pain and chronic paresthesia incidences after VATS for primary spontaneous pneumothorax are not irrelevant ( $8 \%$ and $22 \%$, respectively). However, these complications generally do not significantly impact on patients' daily life, as only $0.5 \%$ of patients required painkillers regularly. Moreover, our results show that pleurodesis technique, 
Table 3 Risk factors for chronic chest paresthesia ${ }^{\dagger}$ : univariable and multivariable analyses by binary logistic regression

\begin{tabular}{|c|c|c|c|c|}
\hline Risk factor & \multicolumn{2}{|c|}{ Univariable analysis } & \multicolumn{2}{|c|}{ Multivariable analysis } \\
\hline Age, years $(+1)$ & $1.01(0.99-1.03)$ & 0.34 & - & - \\
\hline Gender (male vs. female) & $0.79(0.53-1.18)$ & 0.26 & - & - \\
\hline Cannabis smoking (no vs. yes) & $0.63(0.32-1.24)$ & 0.18 & - & - \\
\hline \multicolumn{5}{|l|}{ Pleurodesis technique } \\
\hline Partial pleurectomy & Ref. & & Ref. & \\
\hline Pleural electrocauterization & $0.10(0.06-0.20)$ & $<0.001$ & $0.49(0.02-0.11)$ & $<0.001$ \\
\hline Pleural abrasion & $0.38(0.25-0.59)$ & $<0.001$ & $0.17(0.09-0.31)$ & $<0.001$ \\
\hline Postoperative chest tube stay, days $(+1)$ & $1.05(1.03-1.08)$ & $<0.001$ & $1.92(1.84-1.99)$ & 0.035 \\
\hline
\end{tabular}

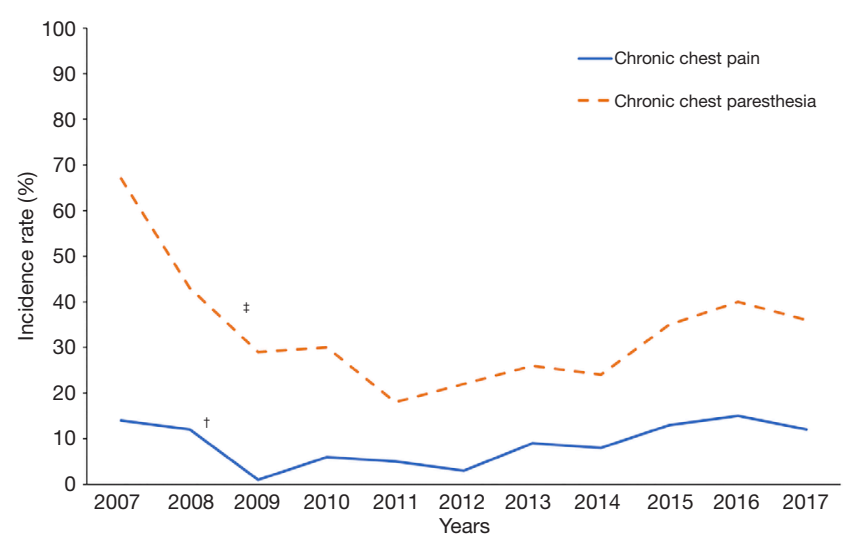

Figure 1 The trend of chronic chest pain and chronic chest paresthesia after VATS for primary spontaneous pneumothorax over the study period $\left(^{\dagger}\right.$ : difference between 2007-2009, $\mathrm{P}=0.008$; ${ }^{\ddagger}$ : difference between 2007-2011, $\mathrm{P}<0.001)$.

chest tube size and postoperative drainage duration are risk factors for chronic chest pain and paresthesia, suggesting that even little changes (i.e., chest tube of smaller size) in our daily practice could improve our patients' long-term outcomes.

The incidence of chronic pain in our study ranks in the lower part of the range reported in the literature after VATS for primary spontaneous pneumothorax (3-63\%) $(1,3-5,8,9)$. Such wide range could be explained by the different definitions used for chronic pain. We have considered only pain $\geq 3$ on NRS, but if we included in chronic pain rate calculation patients referring chest pain of 1-2 on NRS, the incidence of chronic pain in our study would increase from $8 \%$ to $23 \%$. Likewise, Passlick et al. have reported an overall chronic pain rate of $31.7 \%$ after VATS for primary spontaneous pneumothorax and only $3.3 \%$ patients with pain intensity $>50$ on visual analogic scale ranging from 0-100 (3). The use of NRS 3 as cutoff value in chronic pain definition in this study has been dictated by the aim of focusing on pain that is relevant to patients' daily life activities. Reviewing pain intensity rating, NRS 3 pain is described as "bothering" while NRS 2 and NRS 1 respectively as "minimal" and "hardly noticeable".

Another good descriptor of patient chronic pain is the need of analgesics and the frequency of their use. In our study, in agreement with the literature, $<10 \%$ patients still required painkillers to relieve chest discomfort at long-term follow-up, suggesting that chronic pain is predominantly mild (1,3,5,7,10-12).

Regarding chronic chest paresthesia, our data are consistent with those reported in the literature; only few studies assessed paresthesia at long-term followup $(2,7,9,13)$. According to Sihoe et al.'s results, $52.9 \%$ primary spontaneous pneumothorax patients referred chest paresthesia immediately after VATS with only $20 \%$ and $21 \%$ patients still having it respectively at 6 and 
12 months after surgery (2). Similar values have been reported by other authors who have assessed paresthesia ranging between $9.7 \%$ and $60 \%(2,7,9,13)$. Paresthetic discomfort is generally described as an altered sensation (pins and needles, numbness, swollen) localized to lower and antero-lateral chest wall and indefinitely around chest wounds (2). This description of chest altered perception recalls chest dysesthesia with hypoesthesia, hypoalgesia, allodynia and hyperalgesia, which are typical of postoperative neuropathic pain. This suggests that both postsurgical chest pain and paresthesia are in part the results of intercostal nerve injury likely due to camera and instrument compression $(8,14)$.

The common neuropathic etiology of postoperative chest pain and paresthesia may explain why their risk factors are similar. Intercostal nerve injury may be more likely associated with partial pleurectomy, with greater chest tube size and with longer chest tube stay. Partial pleurectomy, by stripping away the parietal pleura from the endothoracic fascia, stretches intercostal nerve endings. Concurrently, the chest tube could injury intercostal nerves by direct compression. Intuitively, using chest tube with greater diameter and leaving it in place for longer time increase the risk of nerve injury, pain and paresthesia. To our knowledge, in the literature no studies investigated possible risk factors for chronic pain and paresthesia in patients undergoing VATS for primary spontaneous pneumothorax. Studies which compare different surgical techniques in this specific patient population evaluated pain and paresthesia only at short-term follow-up (2,3,7,9-11,15-20).

Combining the results of this paper with those of our previous study indicating that pleurodesis technique does not impact on pneumothorax recurrence (21), we conclude that pleural electrocauterization or talc poudrage may be preferred to partial pleurectomy and pleural abrasion in order to reduce the risk of chronic chest pain and paresthesia.

We did not find a significant correlation between either chronic chest pain/chronic chest paresthesia and VATS ports number (uniportal vs. bi-triportal VATS). This finding seems to be in contrast with the literature, which reports higher rate of pain and paresthesia after bitriportal VATS $(7,9,15-20,22)$. However, the majority of these papers looks only at the first 72 hours after surgery, without finding statistically significant differences when looking at long-term follow-up pain scores $(7,9,20)$. Conversely, postoperative chest paresthesia is reported to be significantly higher at 72 hours after multi-port VATS, and this difference is confirmed at long-term follow-up too $(58-94 \%$ vs. $14-35 \%)(7,9,15-18)$. Higher incidence of postoperative paresthesia after multi-port VATS may be explained by the presence of 1 or 2 additional incisions, compared to uniportal approach, which may increase the risk of intercostal nerve damage with development of longterm chest numbness, "pins and needles" and/or swollen sensation (9). Possibly the lack of association between ports number and chronic paresthesia in our study could be due to the small number (4\%) of patients undergoing uniportal approach.

Finally, the progressive reduction of chronic chest paresthesia incidence rate experienced in 2007-2011 in our study period may be explained by the introduction of intercostal nerve block as a routine after VATS for primary spontaneous pneumothorax in some centers.

This study has limitations, mostly due to its multiinstitutional and retrospective nature. To overcome these, every record was defined a priori, clinical and surgical history was rebuilt in detail for each patient by the local surgical team and the data were collected in a shared dataset. Pain and paresthesia at follow-up were evaluated and rated without using clinically validated questionnaires; however, each patient was interviewed using specific and a priori decided questions and pain was rated by NRS. No data were available about pain and paresthesia during the postoperative stay and about perioperative pain management which followed standardized protocol for each center. Though, the same type of surgical procedure was performed in at least two Centers, reducing the impact of different perioperative pain management on the results. Another limitation is the difference in the length of followup of each patient. We included all patients observed for at least 2 months, because in the literature chronic chest pain and paresthesia after surgery are defined as a condition persisting at least 2 months after surgery and other authors have previously used this time limit $(1,2,7,8)$. We observed that chronic chest pain and paresthesia rates were similar between patients observed within a year after surgery and those followed-up for more than 90 months. Moreover, the analysis of the potential risk factors for chronic chest pain and paresthesia were performed by Cox regression model in order to overcome the time bias. Finally, no data about surgeon experience, which could impact on patient postoperative course, are available. Strengths of this study are the large size of the cohort and the comparison of chronic chest pain and paresthesia among patients undergoing different surgical procedures and different 
perioperative chest tube management policies.

In conclusion, chronic chest pain and paresthesia after VATS for primary spontaneous pneumothorax generally do not limit patient daily life activities but in few patients may be clinically relevant complications. In our cohort, chronic chest pain and paresthesia are independently associated with pleurodesis technique, chest tube size and chest tube postoperative duration. This retrospective multicenter study suggests that small changes in daily practice, like using small-size chest tube and removing it early could improve patients' long-term outcomes.

\section{Acknowledgments}

Funding: None.

\section{Footnote}

Reporting Checklist: The authors have completed the STROBE reporting checklist. Available at http://dx.doi. org/10.21037/jtd-20-2860

Data Sharing Statement: Available at http://dx.doi. org/10.21037/jtd-20-2860

Peer Review File: Available at http://dx.doi.org/10.21037/jtd20-2860

Conflicts of Interest: All authors have completed the ICMJE uniform disclosure form (available at http://dx.doi. org/10.21037/jtd-20-2860). PLF serves as an unpaid editorial board member of Journal of Thoracic Disease from Sep 2020 to Aug 2022. AI serves as an unpaid editorial board member of Fournal of Thoracic Disease from Jan 2020 to Dec 2021. The other authors have no conflicts of interest to declare.

Ethical Statement: The authors are accountable for all aspects of the work in ensuring that questions related to the accuracy or integrity of any part of the work are appropriately investigated and resolved; the study was conducted in accordance with the Declaration of Helsinki (as revised in 2013). The study was approved by the institutional ethics committee (n: 64/2018). Individual consent for this retrospective analysis was waived.

Open Access Statement: This is an Open Access article distributed in accordance with the Creative Commons
Attribution-NonCommercial-NoDerivs 4.0 International License (CC BY-NC-ND 4.0), which permits the noncommercial replication and distribution of the article with the strict proviso that no changes or edits are made and the original work is properly cited (including links to both the formal publication through the relevant DOI and the license). See: https://creativecommons.org/licenses/by-nc-nd/4.0/.

\section{References}

1. Lang-Lazdunski L, Chapuis O, Bonnet PM, et al. Videothoracoscopic bleb excision and pleural abrasion for the treatment of primary spontaneous pneumothorax: long-term results. Ann Thorac Surg 2003;75:960-5.

2. Sihoe AD, Au SS, Cheung ML, et al. Incidence of chest wall paresthesia after video-assisted thoracic surgery for primary spontaneous pneumothorax. Eur J Cardiothorac Surg 2004;25:1054-8.

3. Passlick B, Born C, Sienel W, et al. Incidence of chronic pain after minimal-invasive surgery for spontaneous pneumothorax. Eur J Cardiothorac Surg 2001;19:355-8.

4. Mouroux J, Elkaïm D, Padovani B, et al. Video-assisted thoracoscopic treatment of spontaneous pneumothorax: technique and results of one hundred cases. J Thorac Cardiovasc Surg 1996;112:385-91.

5. Bertrand PC, Regnard JF, Spaggiari L, et al. Immediate and long-term results after surgical treatment of primary spontaneous pneumothorax by VATS. Ann Thorac Surg 1996;61:1641-5.

6. von Elm E, Altman DG, Egger M, et al. The Strengthening the Reporting of Observational Studies in Epidemiology (STROBE)statement: guidelines for reporting observational studies. J Clin Epidemiol 2008;61:344-9.

7. Salati M, Brunelli A, Xiumè F, et al. Uniportal videoassisted thoracic surgery for primary spontaneous pneumothorax: clinical and economic analysis in comparison to the traditional approach. Interact Cardiovasc Thorac Surg 2008;7:63-6.

8. Macrae WA. Chronic pain after surgery. Br J Anaesth 2001;87:88-98.

9. Jutley RS, Khalil MW, Rocco G. Uniportal vs standard three-port VATS technique for spontaneous pneumothorax: comparison of post-operative pain and residual paraesthesia. Eur J Cardiothorac Surg 2005;28:43-6.

10. Chen JS, Hsu HH, Huang PM, et al. Thoracoscopic pleurodesis for primary spontaneous pneumothorax with high recurrence risk: a prospective randomized trial. Ann 
Surg 2012;255:440-5.

11. Rena O, Massera F, Papalia E, et al. Surgical pleurodesis for Vanderschueren's stage III primary spontaneous pneumothorax. Eur Respir J 2008;31:837-41.

12. Ben-Nun A, Soudack M, Best LA. Video-assisted thoracoscopic surgery for recurrent spontaneous pneumothorax: the long-term benefit. World J Surg 2006;30:285-90.

13. Imperatori A, Rotolo N, Spagnoletti M, et al. Risk factors for postoperative recurrence of spontaneous pneumothorax treated by video-assisted thoracoscopic surgery. Interact Cardiovasc Thorac Surg 2015;20:647-51.

14. Elmore B, Nguyen V, Blank R, et al. Pain Management Following Thoracic Surgery. Thorac Surg Clin 2015;25:393-409.

15. Qin SL, Huang JB, Yang YL, et al. Uniportal versus three-port video-assisted thoracoscopic surgery for spontaneous pneumothorax: a meta-analysis. J Thorac Dis 2015;7:2274-87.

16. Nachira D, Ismail M, Meacci E, et al. Uniportal vs. triportal video-assisted thoracic surgery in the treatment of primary pneumothorax-a propensity matched bicentric study. J Thorac Dis 2018;10:S3712-9.

17. Kang DK, Min HK, Jun HJ, et al. Early outcomes of

Cite this article as: Cattoni M, Rotolo N, Mastromarino MG, Cardillo G, Nosotti M, Mendogni P, Rizzi A, Raveglia F, Siciliani A, Rendina EA, Cagini L, Matricardi A, Filosso PL, Passone E, Margaritora S, Vita ML, Bertoglio P, Viti A, Dominioni L, Imperatori A. Chronic chest pain and paresthesia after video-assisted thoracoscopy for primary pneumothorax. J Thorac Dis 2021;13(2):613-620. doi: 10.21037/jtd-20-2860 single-port video-assisted thoracic surgery for primary spontaneous pneumothorax. Korean J Thorac Cardiovasc Surg 2014;47:384-8.

18. Yang HC, Cho S, Jheon S. Single-incision thoracoscopic surgery for primary spontaneous pneumothorax using the SILS port compared with conventional three-port surgery. Surg Endosc 2013;27:139-45.

19. Xu W, Wang Y, Song J, et al. One-port video-assisted thoracic surgery versus three-port video-assisted thoracic surgery for primary spontaneous pneumothorax: a metaanalysis. Surg Endosc 2017;31:17-24.

20. Young R, McElnay P, Leslie R, et al. Is uniport thoracoscopic surgery less painful than multiple port approaches? Interact Cardiovasc Thorac Surg 2015;20:409-14.

21. Cattoni M, Rotolo N, Mastromarino MG, et al. Analysis of pneumothorax recurrence risk factors in 843 patients who underwent videothoracoscopy for primary spontaneous pneumothorax: results of a multicentric study. Interact Cardiovasc Thorac Surg 2020;31:78-84.

22. Bertolaccini L, Pardolesi A, Brandolini J, et al. Uniportal video-assisted thoracic surgery for pneumothorax and blebs/bullae. J Vis Surg 2017;3:107. 
The questionnaire used for the telephone interviewed performed in order to assess the presence and intensity of ipsilateral chest pain and paresthesia and to verify the need and frequency of pain medications in 920 patients undergoing VATS for primary spontaneous pneumothorax.

Question 1) Do you have any chest pain related to the surgical procedure you performed for primary spontaneous pneumothorax treatment?

Possible answers: yes; no.

Question 2) How do you rate the chest pain using a numerical scale from 0 to 10 considering that 0 means no pain, 1-2 minimal pain, 3-4 discomforting pain, 5-6 distressing pain, 7-8 horrible pain and 9-10 worst pain possible?

Possible answers: $0 ; 1 ; 2 ; 3 ; 4 ; 5 ; 6 ; 7 ; 8 ; 9 ; 10$.

Question 3) If the patient refers to have chest pain, Do you need to use painkillers to control chest pain?

Possible answers: yes; no.

Question 4) If the patient answers yes to question 3, How frequently do you require painkillers?

Possible answers: never; weekly; rarely (once a month).

Question 5) Do you have any altered sensation distinguishable from pain (as pins and needles, numbness, swollen) localized to the chest wall or around the chest wounds of the surgical procedure you performed for primary spontaneous pneumothorax treatment?

Possible answers: yes; no. 